\title{
Caffeine supplementation affects the immunometabolic response to concurrent training
}

\author{
Fabrício Eduardo Rossi ${ }^{1,2 *}$, Valéria Leme Gonçalves Panissa², Paula Aulves Monteiro', José Gerosa-Neto', Érico Chagas Caperuto ${ }^{3}$, \\ Jason Michael Cholewa" ${ }^{4}$, Alessandro Moura Zagatto ${ }^{5}$, Fábio Santos Lira ${ }^{1}$
}

'Exercise and Immunometabolism Research Group, Department of Physical Education, Universidade Estadual Paulista, Presidente Prudente, São Paulo, Brazil

2Department of Sport, School of Physical Education and Sport, University of São Paulo, São Paulo, Brazil

${ }^{3}$ Human Movement Laboratory, Universidade São Judas Tadeu, São Paulo, Brazil

${ }^{4}$ Department of Kinesiology, Coastal Carolina University, Conway, SC, USA

${ }^{5}$ Department of Physical Education, Universidade Estadual Paulista, Bauru, São Paulo, Brazil

The aim of the present study was to investigate the effects of caffeine (CAF) and carbohydrate (CHO) intake on strength performance and its metabolic and inflammatory responses during concurrent training. Seven active males ingested a double-placebo (P), CAF (capsule $5 \mathrm{mg} / \mathrm{kg}$ ) or $\mathrm{CHO}(20 \%$ maltodextrin solution) supplementation before strength exercise. Participants performed three randomized sessions of 5,000-m high-intensity intermittent aerobic exercise at maximal intensity followed by strength exercise, performing after the $\mathrm{P}, \mathrm{CHO}$, and $\mathrm{CAF}$ intake. The blood samples were collected before (pre) and immediately after concurrent strength exercise (post). We found a similar number of repetitions and total volume in all supplementation groups. There was a main effect of time on glucose, lactate, and interleukin (IL)-6 $(P<0.05)$. When compared the changes between groups (postvalues minus prevalues), there was lower glucose in CAF group when compared to CHO group (CAF $=5.0 \pm 10.4$ vs. $\mathrm{CHO}=27.8 \pm 20$ vs. $P=15.1 \pm 14, P=0.031$ ) and higher IL-6 levels (CAF $=11.9 \pm 9.2$ vs. $\mathrm{CHO}=-2.4 \pm 1.7$ vs. $P=4.3 \pm$ 11.7, $P=0.017)$. There was significant interaction for glucose and lactate $(P<0.001)$. In conclusion, $\mathrm{CAF}$ and $\mathrm{CHO}$ intake did not improve strength performance during concurrent strength training in active males. However, CAF affected immunometabolic responses.

Keywords: Metabolism, Inflammation, Performance, Caffeine

\section{INTRODUCTION}

Concurrent exercise is the combination of strength and aerobic exercise during the same session or training program (Leveritt and Abernethy, 1999), and it has been shown to impair long-term strength development (Hickson, 1980; Robineau et al., 2016). Studies suggest that the reduction in performance during a session of strength training (i.e., maximum number of repetitions, intensity, or total volume) after aerobic activity, especially high-intensity intermittent exercise (de Souza et al., 2007; Inoue et al., 2016), can contribute to a long-term impairment compared to strength training performed solely (Cadore et al., 2011; Leveritt and Abernethy, 1999).

Therefore, strategies for attenuating the decrease of strength performance, such as nutritional supplementation preceding high-intensity endurance exercise, are necessary to preserve the elevated levels of translation initiation and protein synthesis (Perez-Schindler et al., 2015).

Caffeine (CAF) ingestion can delay neuromuscular fatigue and increase performance by acting on the central nervous system (Davis et al., 2003). Moreover, it affects $\mathrm{K}^{+}$accumulation in the muscle (Mohr et al., 2011) and the action of $\mathrm{Ca}^{2+}$ in the sarcoplasmic reticulum (SR) (Docherty and Sporer, 2000). Furthermore, it is known that endurance exercise promotes acute metabolic changes during the subsequent strength exercise sessions, resulting in the depletion of glycogen stores (Leveritt and Abernethy, 1999). CAF may improve resistance training performance by inhibiting the glycogen phosphorylase enzymes and attenuating glycogen deple-
${ }^{*}$ Corresponding author: Fabrício E. Rossi (ib http://orcid.org/0000-0002-0594-2529 Department of Physical Education, Paulista State University "Júlio Mesquita Filho", Roberto Simonsen Street. nº 305 - Education Center, Presidente Prudente 19060900, São Paulo, Brazil

Tel: +55-18-32295828, Fax. +55-18-3221-4391, E-mail: rossifabricio@yahoo.com.br Received: January 2, 2017 / Accepted: April 3, 2017
This is an Open Access article distributed under the terms of the Creative Commons Attribution Non-Commercial License (http://creativecommons.org/licenses/by-nc/4.0/) which permits unrestricted non-commercial use, distribution, and reproduction in any medium, provided the original work is properly cited. 


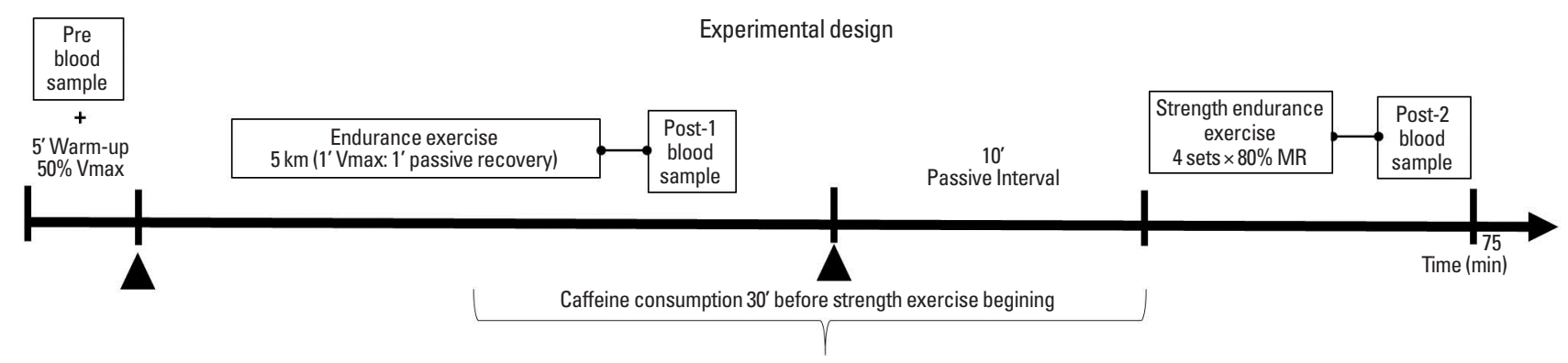

Fig. 1. Experimental design.

Table 1. Caffeine, carbohydrate, and placebo ingestion

\begin{tabular}{lcc}
\hline Placebo & Caffeine & Carbohydrate \\
\hline Calorie-free flavored beverage + cellulose & Calorie-free flavored beverage + caffeine & Maltodextrin solution + cellulose \\
\hline
\end{tabular}

Calorie-free flavored beverage ( $300 \mathrm{~mL})$, carbohydrate $20 \%$ (300 mL), Caffeine $(5 \mathrm{mg} / \mathrm{kg})$, or celulose (2 capsules).

tion (Magkos and Kavouras, 2005).

Moreover, CAF accelerates the release of exercise-induced beta-endorphin, epinephrine, cortisol, and increases interleukin-6 (IL-6) levels, and these alterations in the immunoendocrine response contribute to the benefits of CAF on exercise performance (Phillips et al., 2014; Tauler et al., 2013).

To the best of our knowledge, there is no data in the literature investigating the effects of CAF and carbohydrate $(\mathrm{CHO})$ intakes on concurrent strength performance. Therefore, the purpose of this study was to examine the effects of $\mathrm{CAF}$ and $\mathrm{CHO}$ intake on acute strength performance and the immunoendocrine responses during high-intensity intermittent endurance exercise. Our hypothesis is that the consumption of $\mathrm{CHO}$ and $\mathrm{CAF}$ will reduce skeletal muscle fatigue, improve strength performance and immunoendocrine responses during endurance exercise.

\section{MATERIALS AND METHODS}

\section{Sample and sampling}

Seven healthy active males $(27 \pm 3$ years, $172.0 \pm 0.1 \mathrm{~cm}, 70.5 \pm$ $5.3 \mathrm{~kg}$; $1 \mathrm{RM}$ half-squat, $152.7 \pm 30.8 \mathrm{~kg}$; peak speed in running test, $14.4 \pm 1.3 \mathrm{~km} / \mathrm{hr}$ ), habitual CAF users participated in this study. Participants took part in the study voluntarily after being informed of the procedures, risks, and benefits. All participants signed a consent form. This study was approved by the Ethics Committee. Regarding the effect size, the sample size of the present study had an $80 \%$ power of detecting differences between groups regarding the maximum number of repetitions.

\section{Design}

In previous sessions, the participants performed anthropometric measurements, a graded exercise test to assess peak treadmill speed (Vmax) (MASTER CI, Inbramed, Porto Alegre, Brazil), and one-repetition maximum test (1RM) in Smith machine (Ipiranga, Presidente Prudente, Brazil). After that, the subjects performed three randomized, concurrent exercise sessions (Fig. 1).

\section{Concurrent exercise sessions}

Participants completed a warm-up at $50 \%$ of Vmax for 5 min, and after a 2-min rest interval, the exercise bout was started. The endurance exercise consisted of a $5-\mathrm{km}$ intermittent run on a treadmill, corresponding to $1 \mathrm{~min}$ at the Vmax followed by $1 \mathrm{~min}$ of passive recovery (1:1 effort and pause ratio). After a 10-min passive rest interval, the subjects performed four sets of half-squat at $80 \%$ of $1 \mathrm{RM}$ on a Smith machine (Ipiranga). All sets were performed until failure, and each set was separated by a 2-min rest interval. The maximum number of repetitions performed was recorded, and the total volume was calculated (repetitions $\times$ weight lifted). All tests took place during the same time of the day for each subject. The subjects were instructed to abstain from any strenuous exercise or CAF ingestion at least $48 \mathrm{hr}$ before each testing session and were encouraged to maintain their nutritional and hydration routines.

\section{$\mathrm{CAF}, \mathrm{CHO}$, and $\mathrm{P}$ ingestion}

The CAF, $\mathrm{CHO}$, and $\mathrm{P}$ were ingested according to Table 1.

For all three experimental groups, subjects consumed a 300-mL calorie-free flavored (i.e., lemon) beverage (Clight, Nutriguía, Brazil) and ingested two capsules, as follows: P group: subjects ingested 
the beverage and two cellulose capsules; CAF group: subjects ingested the beverage and $5 \mathrm{mg} / \mathrm{kg}$ (control body weight) of pure CAF (Uniformula manipulation pharmacy, Presidente Prudente, Brazil); $\mathrm{CHO}$ group: subjects ingested a $20 \%$ maltodextrin solution (Athletica Nutrition, ADS Laboratório Nutricional Ltda, Matão, Brazil) diluted in $300 \mathrm{~mL}$ of water and two cellulose capsules.

\section{Blood sampling and analyses}

Blood samples were collected in P, CHO, and CAF groups. Glucose and lactate were assessed using commercial kits (Labtest, São Paulo, Brazil). Nonester fatty acid (NEFA) was assessed by a colorimetric method with a commercial kit (Wako Diagnostics, 1025 Terra Bella Ave, Suite A Mountain View, CA, USA). Cytokines (IL-6, and tumor necrosis factor [TNF]- $\alpha$ ) were assessed using ELISA commercial kits (Affymetrix/eBioscience, São Paulo, Brasil).

\section{Statistical analysis}

The data was analyzed using SAS 9.2 (SAS Institute Inc., Cary,

Table 2. The maximum number of repetitions and total volume performed $(\mathrm{kg})$ in placebo, caffeine, and maltodextrin group

\begin{tabular}{lccc}
\hline Variable & Placebo & Caffeine & Carbohydrate \\
\hline Set 1 & $17.0 \pm 8.2$ & $14.6 \pm 5.3$ & $13.9 \pm 7.4$ \\
Set 2* & $11.6 \pm 3.8$ & $11.8 \pm 2.3$ & $11.4 \pm 6.0$ \\
Set $3^{*}$ & $9.3 \pm 2.8$ & $10.7 \pm 2.7$ & $9.7 \pm 4.8$ \\
Set $4^{*}$ & $8.6 \pm 3.0$ & $7.1 \pm 2.5^{\dagger, \pm}$ & $9.8 \pm 6.3$ \\
MNR & $46.4 \pm 14.8$ & $44.3 \pm 6.8$ & $44.9 \pm 23.4$ \\
Total volume & $5,631.9 \pm 2,245.8$ & $5,413.1 \pm 1,387.5$ & $5,616.1 \pm 3,189.7$ \\
\hline
\end{tabular}

Values are presented as mean \pm standard deviation.

MNR, maximal number of repetition

*Tukey post hoc test with $P$-value $<0.05$ compared to set 1 . Tukey post hoc test with $P$-value $<0.05$ compared to set 2 . ${ }^{\ddagger}$ Tukey post hoc test with $P$-value $<0.05$ compared to set 3 .
NC, USA) and presented as mean and standard deviation. Linear mixed models were used to compare the maximum number of repetitions during each set in different groups (group $\times$ set), as well as blood variables in different groups over time (group $\times$ time). The Tukey post boc was used if significant differences were found. The "mean differences" (postvalues minus prevalues) were calculated and analyzed by one-way analysis of variance. If a significant difference was found, Tukey post hoc was used again. The effect size was calculated. Statistical significance was set at $P<0.05$.

\section{RESULTS}

The high-intensity intermittent exercise was concluded in $42.9 \pm 4 \mathrm{~min}$. The maximum number of repetitions during each set per groups is presented in Table 2. For the maximum number of repetitions, there was a main effect of set $(F[3,66]=11.7$, $P<0.001)$ with higher maximum number of repetitions performed during the first set than during the second set $(P=0.020)$, third set $(P<0.001)$ and fourth set $(P<0.001)$.

Table 3 showed the metabolic variables in $\mathrm{P}, \mathrm{CAF}$, and $\mathrm{CHO}$ groups.

Regarding glucose, there was a significant interaction $(P=$ 0.019, $\mathrm{ES}=0.48$ ). Post hoc analysis found higher values for $\mathrm{CHO}$ compared to $\mathrm{P}$ postexercise. When compared the delta between condition (postvalues minus prevalues), there was lower values in $\mathrm{CAF}$ in relation to $\mathrm{CHO}(\mathrm{CAF}=5.0 \pm 10.4$ vs. $\mathrm{CHO}=27.8 \pm 20$ vs. $\mathrm{P}=15.1 \pm 14, P=0.031$ ).

In relation to lactate, there was a main effect of time $(P<0.001$, $\mathrm{ES}=0.88)$ but there was no difference between condition and interaction $(P>0.05)$.

About NEFA, there was no a main effect of time, interaction

Table 3. Metabolic variables in placebo, caffeine, and carbohydrate groups

\begin{tabular}{|c|c|c|c|c|c|c|}
\hline Variable & Placebo & CV (\%) & Caffeine & CV (\%) & Carbohydrate & CV (\%) \\
\hline \multicolumn{7}{|c|}{ Glucose (mg/dL) } \\
\hline Pre & $94.8 \pm 7.8$ & 2.8 & $93.8 \pm 7.7$ & 1.8 & $101.9 \pm 12.1$ & 2.9 \\
\hline Post & $109.9 \pm 15.1$ & 5.8 & $98.8 \pm 10.5$ & 1.9 & $129.7 \pm 10.7^{*}$ & 6.2 \\
\hline \multicolumn{7}{|c|}{ Lactate (mmol/L) } \\
\hline Pre & $1.2 \pm 0.3$ & 2.3 & $1.3 \pm 0.4$ & 5.9 & $1.5 \pm 0.1$ & 2.8 \\
\hline Post & $6.2 \pm 1.8$ & 3.5 & $6.8 \pm 2.7$ & 2.4 & $6.4 \pm 2.3$ & 3.2 \\
\hline \multicolumn{7}{|c|}{$\mathrm{NEFA}$ (mmol/L) } \\
\hline Pre & $0.50 \pm 0.1$ & 4.1 & $0.70 \pm 0.2$ & 7.0 & $0.73 \pm 0.1$ & 7.1 \\
\hline Post & $0.54 \pm 0.1$ & 1.4 & $0.70 \pm 0.2$ & 4.4 & $0.80 \pm 0.1$ & 8.3 \\
\hline
\end{tabular}

Values are presented as mean \pm standard deviation.

$\mathrm{CV}$, coefficient of variation; NEFA, nonesterified fatty acids.

*Statistically significant difference between placebo and carbohydrate groups. 
Table 4. Inflammatory variables in placebo, caffeine, and carbohydrate groups

\begin{tabular}{lclc}
\hline Variable & Placebo & Caffeine & Carbohydrate \\
\hline IL-6 $(\mathrm{pg} / \mathrm{mL})$ & & & \\
Pre & $18.5 \pm 9.0$ & $16.9 \pm 6.5$ & $21.7 \pm 6.7$ \\
Post & $22.8 \pm 7.2$ & $28.8 \pm 12.1^{*}$ & $19.4 \pm 6.7$ \\
TNF- $\alpha(\mathrm{pg} / \mathrm{mL})$ & & & \\
Pre & $9.7 \pm 7.66$ & $11.2 \pm 3.6$ & $10.6 \pm 3.6$ \\
Post & $11.1 \pm 3.5$ & $13.4 \pm 5.6$ & $11.9 \pm 3.2$ \\
\hline
\end{tabular}

Values are presented as mean \pm standard deviation.

IL, interleukin; TNF, tumor necrosis factor.

${ }^{*}$ Statistically significant difference between caffeine and carbohydrate groups.

but there was a trend to difference between condition $(P=0.060$, $\mathrm{ES}=0.50)$

Table 4 presented the inflammatory variables in $\mathrm{P}, \mathrm{CAF}$, and $\mathrm{CHO}$ groups.

Regarding IL-6, there was no significant difference between condition but there was significant interaction $(P=0.024)$, post boc showed higher IL- 6 only for CAF condition postexercise compared to preexercise $(P=0.039)$ and trend a main effect of time $(P=0.064, \mathrm{ES}=0.46)$. When compared the changes between condition again $(\triangle$, Fig. 2$)$, there was higher values in $\mathrm{CAF}$ in relation to $\mathrm{CHO}(\mathrm{CAF}=11.9 \pm 9.2$ vs. $\mathrm{CHO}=-2.4 \pm 1.7$ vs. $\mathrm{P}=4.3 \pm$ $11.7, P=0.017)$.

In relation to TNF- $\alpha$, there was no a main effect for condition $(P=0.065)$ and interaction $(P>0.05)$ but there was a trend across time $(P=0.072, \mathrm{ES}=0.50)$.

\section{DISCUSSION}

The main finding of the present study was that $\mathrm{CAF}$ and $\mathrm{CHO}$ intakes did not improve performance in concurrent strength sessions, and CAF consumption led to higher IL-6 level after the concurrent strength exercise.

Despite the energy availability provided by $\mathrm{CHO}$ consumption, which sustained high blood glucose levels, strength performance was not decreased. This finding could be explained by the inability or difficulty of muscle cells to uptake and utilize the glucose, which is reinforced by the lack of correlation between glucose and lactate in $\mathrm{CHO}$ group compared to the $\mathrm{P}$ group, where there was a correlation between the same variables. This possibly explains the lack of increase in lactate concentrations in the $\mathrm{CHO}$ group.

An explanation to understand such findings is the exercise protocol used, characterized as high intensity, which produces a metabolic stressful environment. An indication of that is the increase of $\mathrm{H}^{+}$ions, making the cellular environment more acidic. This

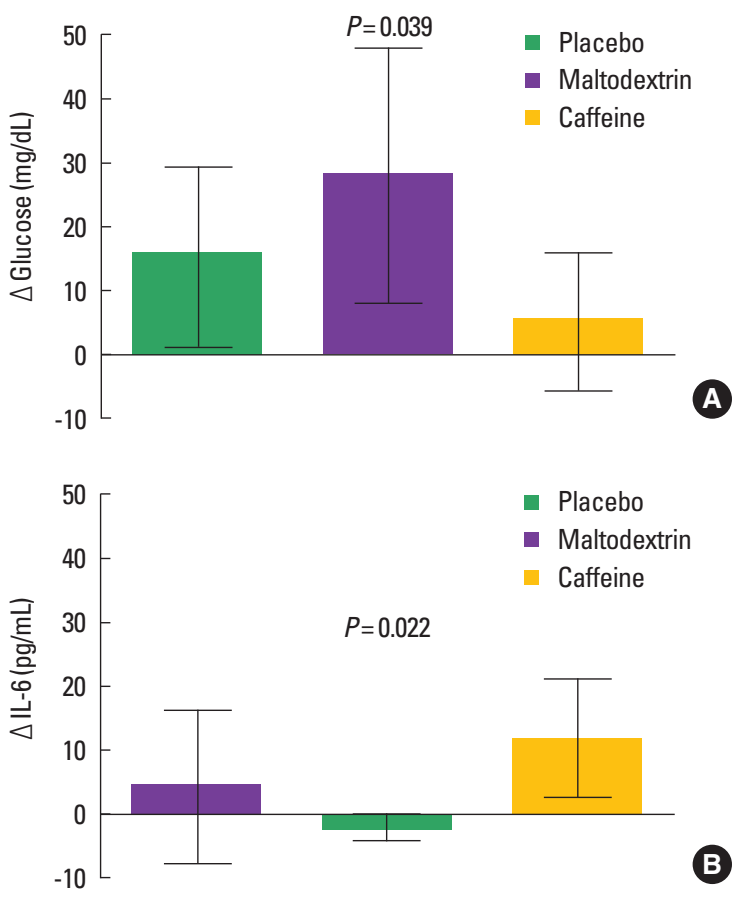

Fig. 2. (A) Comparison between placebo, caffeine, and carbohydrate groups on the absolute variation $(\Delta)$ after concurrent exercise sessions for glucose (mg/ dL). (B) Comparison between placebo, caffeine, and carbohydrate groups on the absolute variation $(\Delta)$ after concurrent exercise sessions for interleukin (IL)$6(\mathrm{pg} / \mathrm{mL})$.

acidity may adversely affect various mechanisms, such as the reduced SR action that impairs muscle contraction, and phosphofructokinase inhibition, impairing energy metabolism. In agreement, the energy deficit also impairs the action of ATPase in the $\mathrm{Na}^{+}$and $\mathrm{K}^{+}$channels in the plasma membrane and $\mathrm{Ca}^{2+}$ channels in SR. Moreover, it seems that $\mathrm{Ca}^{2+}$ has a relevant role in glucose transporter 4 (GLUT4) translocation in parallel to AMP protein kinase action during exercise (Duhamel et al., 2007). Accordingly, if $\mathrm{Ca}^{2+}$ release and uptake are impaired, there is also impairment of the GLUT4 translocation, thus hindering glucose uptake. However, more studies are needed to elucidate these mechanisms.

Our findings show that CAF intake also did not attenuate fatigue during the concurrent strength exercise. In agreement with our results, Pettersen et al. (2014) and Lee et al. (2014) observed that CAF ingestion $(5 \mathrm{mg} / \mathrm{kg}$ ) had no ergogenic effect on strength performance. However, Pallares et al. (2013) tested the effect of three different doses of $\mathrm{CAF}(3,6$, and $9 \mathrm{mg} / \mathrm{kg})$ on four progressive loads $(25 \%, 50 \%, 75 \%$, and $90 \%$ 1MR). They found that the three doses were effective in prolonging the time to exhaustion, and $3 \mathrm{mg} / \mathrm{kg}$ was sufficient to improve the propulsion speed for lower loads ( $25 \%$ and $50 \%$ 1MR), while higher doses (6 and 9 
$\mathrm{mg} / \mathrm{kg}$, respectively) were required for moderate (75\% 1MR) and heavy (90\% 1MR ) loads.

Regarding IL-6, we found higher levels immediately after concurrent strength only in the CAF group. Few studies have examined effects of CAF consumption on endurance exercise and immunoendocrine response (Phillips et al., 2014; Tauler et al., 2013). However, the cytokines, specifically IL- 6 and TNF- $\alpha$, have been considered an energetic sensor, in a hormone-like manner, that can mobilize extracellular glucose and free fatty acids during exercise (Febbraio and Pedersen, 2005). Collectively with our data, this suggests that CAF consumption during concurrent strength training can promote changes in the immunoendocrine response, and also facilitate lipolysis and glycogenolysis to provide energy supply for the skeletal muscle and other tissues during and after exercise. Therefore, CAF can affect the immunometabolic response of concurrent exercise. However, future research is needed to better understanding.

The present study has some limitations. First, the experimental design differs from others because it is a concurrent strength protocol, which consists of high-intensity intermittent endurance exercise performed before strength exercise. Second, although scientific literature claims that peak plasma concentration of CAF may occur between 15 and $120 \mathrm{~min}$ after oral ingestion (Magkos and Kavouras, 2005), it is possible that the allotted time for absorption of the CAF before the strength exercise $(30 \mathrm{~min}$ ) was not sufficient. However, more studies are necessary to better understand the mechanisms involved in time-release and effective nutritional supplementation.

In conclusion, $\mathrm{CAF}$ and $\mathrm{CHO}$ intake did not improve strength performance during concurrent strength exercise in active males but promoted changes in immunometabolic responses.

\section{CONFLICT OF INTEREST}

No potential conflict of interest relevant to this article was reported.

\section{ACKNOWLEDGMENTS}

The São Paulo Research Foundation (FAPESP; 2013/25310-2).

\section{REFERENCES}

Cadore EL, Pinto RS, Pinto SS, Alberton CL, Correa CS, Tartaruga MP, Silva EM, Almeida AP, Trindade GT, Kruel LF. Effects of strength, en- durance, and concurrent training on aerobic power and dynamic neuromuscular economy in elderly men. J Strength Cond Res 2011;25:758766.

Davis JM, Zhao Z, Stock HS, Mehl KA, Buggy J, Hand GA. Central nervous system effects of caffeine and adenosine on fatigue. Am J Physiol Regul Integr Comp Physiol 2003;284:R399-404.

de Souza EO, Tricoli V, Franchini E, Paulo AC, Regazzini M, Ugrinowitsch $\mathrm{C}$. Acute effect of two aerobic exercise modes on maximum strength and strength endurance. J Strength Cond Res 2007;21:12861290.

Docherty D, Sporer B. A proposed model for examining the interference phenomenon between concurrent aerobic and strength training. Sports Med 2000;30:385-394.

Duhamel TA, Green HJ, Stewart RD, Foley KP, Smith IC, Ouyang J. Muscle metabolic, $\mathrm{SR} \mathrm{Ca}(2+)$-cycling responses to prolonged cycling, with and without glucose supplementation. J Appl Physiol (1985) 2007; 103:1986-1998.

Febbraio MA, Pedersen BK. Contraction-induced myokine production and release: is skeletal muscle an endocrine organ? Exerc Sport Sci Rev 2005;33:114-119.

Hickson RC. Interference of strength development by simultaneously training for strength and endurance. Eur J Appl Physiol Occup Physiol 1980;45:255-263.

Inoue DS, Panissa VL, Monteiro PA, Gerosa-Neto J, Rossi FE, Antunes BM, Franchini E, Cholewa JM, Gobbo LA, Lira FS. Immunometabolic responses to concurrent training: the effects of exercise order in recreational weightlifters. J Strength Cond Res 2016;30:1960-1967.

Lee CL, Cheng CF, Lee CJ, Kuo YH, Chang WD. Co-ingestion of caffeine and carbohydrate after meal does not improve performance at highintensity intermittent sprints with short recovery times. Eur J Appl Physiol 2014;114:1533-1543.

Leveritt M, Abernethy PJ. Acute effects of high-intensity endurance exercise on subsequent resistance activity. J Strength Cond Res 1999;13:4751.

Magkos F, Kavouras SA. Caffeine use in sports, pharmacokinetics in man, and cellular mechanisms of action. Crit Rev Food Sci Nutr 2005; 45:535-562.

Mohr M, Nielsen JJ, Bangsbo J. Caffeine intake improves intense intermittent exercise performance and reduces muscle interstitial potassium accumulation. J Appl Physiol (1985) 2011;111:1372-1379.

Pallarés JG, Fernández-Elías VE, Ortega JF, Muñoz G, Muñoz-Guerra J, Mora-Rodríguez R. Neuromuscular responses to incremental caffeine doses: performance and side effects. Med Sci Sports Exerc 2013;45: 2184-2192.

Perez-Schindler J, Hamilton DL, Moore DR, Baar K, Philp A. Nutritional 
strategies to support concurrent training. Eur J Sport Sci 2015;15:41-52.

Pettersen SA, Krustrup P, Bendiksen M, Randers MB, Brito J, Bangsbo J, Jin Y, Mohr M. Caffeine supplementation does not affect match activities and fatigue resistance during match play in young football players. J Sports Sci 2014;32:1958-1965.

Phillips SM, Findlay S, Kavaliauskas M, Grant MC. The influence of serial carbohydrate mouth rinsing on power output during a cycle sprint. J
Sports Sci Med 2014;13:252-258.

Robineau J, Babault N, Piscione J, Lacome M, Bigard AX. Specific training effects of concurrent aerobic and strength exercises depend on recovery duration. J Strength Cond Res 2016;30:672-683.

Tauler P, Martínez S, Moreno C, Monjo M, Martínez P, Aguiló A. Effects of caffeine on the inflammatory response induced by a $15-\mathrm{km}$ run competition. Med Sci Sports Exerc 2013;45:1269-1276. 